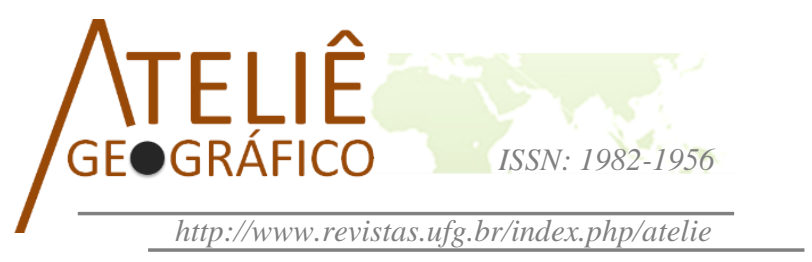

\title{
A deriva e a psicogeografia e suas possibilidades para os tra- balhos de campo em Geografia Urbana
}

\author{
The drift and psychogeography and its possibilities for field \\ work in Urban Geography
}

\section{La deriva y psicogeografía y sus posibilidades de trabajo de campo en Geografía Urbana}

\author{
Glauco Roberto Gonçalves \\ Universidade Federal de Goiás \\ glauco.goncalves@ufg.br
}

\begin{abstract}
Resumo
Deriva e psicogeografia são propostas prático-teóricas elaboradas pela Internacional Situacionista com o intuito de desvendar criticamente o cotidiano atrelado ao processo de urbanização. Este artigo oferece um percurso constitutivo destas propostas ao longo da história da Internacional Situacionista e tenta estabelecer as relações e razões pelas quais a deriva e a psicogeografia constituem ferramentas de grande valia para os trabalhos de campo em Geografia Urbana.

Palavras-chave: psicogeografia; deriva; Internacional Situacionista; trabalho de campo em Geografia Urbana; urbano e vida cotidiana.
\end{abstract}

\begin{abstract}
Drift and psychogeography are both practical and theoretical Situationist International's proposals, developed in order to critically unveil the daily life linked to the urbanization process. This article offers a constitutive pathway of these proposals along the Situationist International's history and tries to establish the relationships and reasons why the drift and psychogeography are valuable tools for field work in Urban Geography.

Keywords: psychogeography; drift; Situationist International; Fieldwork in Urban Geography; urban and everyday life.

\section{Resumen}

La deriva y psicogeografía son propuestas teórico-prácticos desarrollados por la Internacional Situacionista con el fin de desvelar críticamente el cotidiano relacionado con el proceso de urbanización. En este artículo se ofrece una vía constitutiva de estas propuestas a lo largo de la historia de la Internacional Situacionista y trata de establecer relaciones y razones por las cuales la deriva y psicogeografía son herramientas valiosas para el trabajo de campo en la geografía urbana.
\end{abstract}


Palabras clave: psicogeografía; la deriva; Internacional Situacionista; El trabajo de campo en Geografía Urbana; la vida urbana y cotidiana.

\section{Introdução}

As primeiras proposições sobre a psicogeografia e a deriva aparecem na revista Potlatch publicada pela Internacional Letrista, antecessora da Internacional Situacionista. Tais proposições foram cruciais para estes grupos e foram abordadas em textos e relatos (e praticada no tecido de várias cidades) ao longo das décadas de cinquenta, sessenta e setenta. Longe de ter um caráter de pesquisa de campo, com finalidade científica, as derivas e a psicogeografia eram realizadas buscando o reconhecimento crítico, com embasamento teórico, da realidade urbana e da forma de efetivação (e fundamentalmente de transformação) da vida cotidiana nas cidades.

Neste artigo tenta-se compreender as possibilidades e potencialidades da deriva e da psicogeografia para a realização de trabalhos de campo em geografia urbana. Para tal busca-se seus fundamentos teórico-metodológicos nos debates da Internacional Letrista, bem como na Internacional Situacionista.

\section{A psicogeografia}

A psicogeografia foi uma das ações prático teóricas dos letristas e situacionistas. Definida por eles como o "Estudo dos efeitos do meio geográfico, conscientemente planejado ou não, que agem diretamente sobre o comportamento afetivo dos indivíduos" (JACQUES, 2003, p. 65); foi amplamente discutida abordada e posta em ação já durante a I.L, estando presente com frequência em Potlatch ${ }^{1}$ e seguiu assim sendo na IS. Anselm Jappe afirma que a psicogeografia é o "termo pelo qual [os letristas] designam a observação sistemática dos efeitos produzidos pelas diferentes ambiências urbanas sobre o estado da alma" (JAPPE, 1998, p. 93). Este autor lembra que os letrista publicaram em Potlatch vários relatos psicogeográficos. Já Paola B. Jacques afirma que a "psicogeografia seria então uma geografia afetiva, subjetiva, que buscava cartografar as diferentes ambiências psíquicas provocadas basicamente pelas perambulações urbanas que eram as derivas situacionistas" (JACQUES, 2003, p. 23).

Mais uma vez aqui, como foi característica geral das propositivas

\footnotetext{
${ }^{1}$ Desde o primeiro número de Potlatch a psicogeografia configurou-se como uma das mais duradouras propostas prático-teóricas dos letristas/situacionistas. Raras foram as ideias e tentativas que seguiram sendo válidas e usuais ao grupo. É bem verdade que, sobretudo no primeiro número de Potlatch, a noção de psicogeografia atrelava-se à situação e ambas, embora estivem imbricadas na ampliação das potências do vivido, da cotidianidade, não detinham ainda o poderoso arcabouço transformador e revolucionário que vão adquirindo com o desenvolvimento crítico e propositivo do grupo. O texto do primeiro número de Potlatch (Jogo psicogeográfico da semana) sugere que uma casa seja preparada, juntando os amigos, bebidas e criando então uma ambiência favorável está dada a situação. É curioso ressaltar que a noção de situação, que passa a ser a aposta primordial de transformação situacionistas, já aparece no primeiro número da revista internacional letrista, embora sem a mesma potência, mas já apontando na cotidianidade o caminho de superação da sociedade vigente.
} 
letristas/situacionistas, a psicogeografia é uma tentativa posta em curso almejando mobilizar certos conhecimentos críticos sobre a cidade não pelo plano da teoria, mas pelo plano do vivido. Percorrendo a cidade, usando-a, o corpo (e a alma) se deparava com as consequências trazidas pelo planejamento urbano.

\begin{abstract}
É possível, portanto, estabelecer uma relação intrínseca com o plano afetivo, em como o urbanismo "pesa" sobre o corpo. Mais além, as descrições psicogeográficas, atingidas através das derivas, estabelecem novos mapeamentos, espaços e lugares transitórios, constrói um relevo para além do visível, mais real do que o "relevo real". A psicogeografia é ao mesmo tempo crítica do urbanismo funcionalista e proposição de seu outro, o urbanismo unitário: "a construção de ambiências que permitam não expressar, mas sim suscitar novas sensações". É importante também frisar que a psicogeografia e o urbanismo unitário são os primeiros pontos de contato da IL com outros grupos europeus que vieram a compor a Internacional Situacionista. (MAGALHÃES, 2011, p. 18)
\end{abstract}

A psicogeografia era, portanto, também uma resposta ao funcionalismo que impunha sua concepção de cidade; pretendendo se contrapor a ele, deixando claro, localizando, seus graves equívocos sobre o cotidiano urbano e as (im)possibilidades de usar a cidade. Assim, a psicogeografia ao pôr à prova o planejamento executado pelos funcionalistas 2 era um meio pelo qual se identificava a impossibilidade de realizar uma vida apaixonante, mostrando o descompasso entre a função, o desejo, e o lúdico. Em um momento (não muito diferente do atual) em que se procurava no planejamento sanar os problemas da vida urbana, os letristas (como também depois os situacionistas) percorriam a cidade, buscavam se apropriar dela, deixando claro os problemas do ato de planejar e suas imposições inviabilizando a possibilidade de viver.

Como lembra MAGALHÃES, a psicogeografia foi um ponto de aproximação entre os letristas e outros grupos que viriam a formar a Internacional Situacionista. Merece destaque a figura de Ralph Rumney que era membro do grupo (de um homem só!) "Comitê Psicogeográfico de Londres" (London Psichogeographical Association)3, e que se uniu à I.S nos primeiros momentos de sua formação, e logo se debruçou sobre as

\footnotetext{
${ }^{2} \mathrm{O}$ enfoque é dado aos funcionalistas pois, como se sabe, era a escola de arquitetura e urbanismo que reinava absoluta naquele momento, e impunha suas ideias sobre o espaço com ênfase e em profusão. Entretanto, as concepções de urbanismo que se estabeleceram anteriormente, sobretudo desde Haussmann, também eram postas à prova, e via de regra, eram criticadas pelos letristas/situacionistas por sua impossibilidade de tornar ou auxiliar a construção da arte de viver. No texto "Os funcionalistas e os situacionistas" procuro expor a importância que a crítica aos funcionalistas adquire dentro do projeto de transformação total da vida pelos situacionistas.

${ }^{3}$ Vale lembrar, se valendo da observação de MAGALHÃES (2011, p. 35) que tal grupo foi também formado durante o encontro de Cosio d'Arosca. É curioso notar que na Inglaterra a psicogeografia encontra ressonância até hoje.
} 
atividades psicogeográficas. Em um texto sobre a incursão de Rumney4 é possível compreender um pouco mais sobre o tema:

Os exploradores antigos sofreram muitas perdas à custa das quais chegou-se ao conhecimento de uma geografia objetiva. Não é de estranhar que também haja vítimas entre os novos pesquisadores, exploradores do espaço social e das maneiras como ele é usado.

As armadilhas são outras, mas o objetivo também é de outra natureza: procura-se chegar a um uso apaixonante da vida. É compreensível que se esbarre nas defesas do mundo do tédio. O fato é que Rumney acaba de desaparecer e seu pai ainda não foi procurá-lo. A selva de Veneza foi mais forte e se fechou sobre um jovem promissor cheio de vida, que se perde, que se dissolve, entre nossas múltiplas lembranças. (JACQUES, 2003, p. 78)

Também como o desvio e a decomposição ${ }^{5}$, a psicogeografia esteve presente tanto na Internacional Letristas como na Situacionista sendo um dos modos pelo qual o entrelaçamento entre a teoria e a prática se davam como meio de destituir o entendimento corriqueiro de ambos e construir uma vida apaixonante. Simultaneamente, a psicogeografia oferecia a possibilidade de, no contato prático e profundo com a cidade, realizar uma crítica voraz sobre o meio e a forma de produzi-la e de (não) usá-la. No texto "Esboço psicogeográfico do Les Halles de Paris"6 é possível identificar este entrecruzamento entre a teoria crítica e a prática transformadora almejando transformar a cidade para mudar radicalmente a vida.

O mundo em que vivemos parece, sobretudo sob seu aspecto material, cada dia mais estreito. Chega a nos abafar. Sofremos profundamente sua influência; reagimos-lhe de acordo com nossos instintos em vez de reagirmos de acordo com nossas aspirações. Em suma, esse mundo comanda nosso modo de ser, e por isso, nos esmaga. Se ele não for reformulado - ou melhor, estilhaçado - não haverá num nível superior, o modo de vida[...]

Mas o que desejamos é uma intervenção direta, efetiva, que leve, após indispensáveis estudos preliminares - e nesse ponto a psico-

\footnotetext{
4"Veneza venceu Ralph Rumney" publicado na I.S n. 1, jun. de 1958.

${ }^{5}$ Entende-se por desvio o uso de fragmento de texto de outro autor alterando-o e resignificando-o em favor das ideias e proposições que se quer apresentar. Entretanto, o desvio para além da mudança do autor é também, e sobretudo, sua permanência. "Para Isou, especificamente no campo artístico: uma colagem que reaproveita elementos já existentes para a criação do novo. Para Debord e os situacionistas o desvio se amplia para o campo das ideias. Conceitos que julgam ultrapassados, de terem se destituído de seu conteúdo crítico, ou até mesmo de opiniões contrárias as suas, são passíveis de serem desviados.” (MAGALHÃES, 2011, p. 9). Já a decomposição deve ser entendida como o meio pelo qual a burguesia "[...] organiza a banalização das descobertas subversivas e as difunde amplamente, depois de esterilizá-las” (JACQUES, 2003, p. 44).

${ }^{6}$ I.S n. 2, Dezembro de 1958.
} 
geografia será de grande importância -, a instaurar novas ambiências, situacionistas, cuja características essenciais são a curta duração e a mudança constante. (JACQUES, 2003, pp. 79-80)

É possível ver, com certa clareza, que o entendimento situacionista sobre a cidade passa irremediavelmente por sua capacidade castradora e inibidora das aspirações, do desejo, do lúdico. O entrelaçamento entre a cidade e o urbanismo nela aplicado e a incapacidade de viver é colossal, e se faz impossível transformar total e profundamente um sem a transformação (total e profunda) do outro. A psicogeografia auxilia a identificar e evidenciar que as formas e os conteúdos da cidade inviabilizam a vida.

No texto "Introdução a uma crítica à geografia urbana" Debord avança na caracterização da psicogeografia e de sua relação com a deriva. Também neste texto se pode identificar alguns caminhos para a realização de um estudo psicogeográfico (que é para esta pesquisa de grande interesse) que identifique desníveis e fronteiras psicogeográficas, bem como zonas de climas psíquicos. Debord é enfático ao identificar a importância do cotidiano e dos desdobramentos da cidade sobre ele, fato que move sua crítica à geografia urbana e põe em curso a necessidade de estudos psicogeográficos para além do plano, do tecido urbano, chegar no entrecruzamento da cidade planejada e da experiência vivida.

\begin{abstract}
A psicogeografia seria o estudo das leis exatas e dos efeitos precisos do meio geográfico planejado conscientemente ou não, que agem diretamente sobre o comportamento afetivo dos indivíduos. $\mathrm{O}$ adjetivo psicogeográfico, que guarda uma impressão interessante, pode portanto ser aplicado aos dados estabelecidos por esse gênero de pesquisa, aos resultados de sua influência sobre os sentimentos humanos e até, de modo mais geral, a qualquer situação ou conduta que pareçam provir do mesmo espírito de descoberta[...] Hoje, o principal problema que o urbanismo tem a resolver consiste em melhorar o tráfego do crescente número de automotores. É possível que no futuro se dedique a construções, igualmente utilitárias, que levem em consideração as potencialidades psicogeográficas[...] A brusca mudança de ambiências numa rua, numa distância de poucos metros; a divisão patente de uma cidade em zonas de climas psíquicos definidos; a linha de maior declive - sem relação com o desnível - que devem seguir os passeios a esmo; o aspecto atraente e repulsivo de certos lugares; tudo isso parece deixado de lado. Pelo menos, nunca é percebido como dependente de causas que podem ser esclarecidas por uma análise mais profunda, e das quais se pode tirar partido. (JACQUES, 2003, pp. 41-42)
\end{abstract}

A psicogeografia tem na deriva um importante auxílio. Também é possível ver, na citação abaixo, que a psicogeografia pode se valer de materiais cartográficos e estatísticos, bem como de pesquisas, mas que só são legitimados quando postas em curso percorrendo a cidade em derivas. Embora não seja textualmente evidenciado não é difícil 
perceber que está previsto no uso destes materiais (gráficos, mapas ${ }^{7}$, estudos) a prática do desvio, que os recondiciona para localiza-los na construção de uma nova e superior forma de viver.

\begin{abstract}
Os recursos da psicogeografia são numerosos e variados. O primeiro e mais sólido é a deriva experimental. A deriva é um modo de comportamento experimental numa sociedade urbana. Além de um modo de ação, é um meio de conhecimento, especialmente no que se refere à psicogeografia e à teoria do urbanismo unitário. Os outros meios, como a leitura de fotos aéreas e de mapas, o estudo de estatísticas e de gráficos ou de resultados de pesquisas sociológicas, são teóricos e não possuem este lado ativo e direto do qual pertence à deriva experimental. No entanto, é graças a eles que podemos ter uma primeira representação do meio a estudar. E o resultado desse estudo pode, em retorno, modificar essas representações cartográficas e intelectuais no sentido de uma maior complexidade, de um enriquecimento. (JACQUES, 2003, p. 80)
\end{abstract}

As tentativas psicogeográficas de parte do grupo que compunha a I.L, em determinado momento, flertaram com um entendimento fenomênico (husserliano) do urbano, como se através dos sentidos, sobretudo da observação, fosse possível avançar no entendimento (e no sentimento) das contradições e cerceamentos postos pela forma de produzir a cidade. Em decorrência disto, e tão somente uma única vez, em Potlach $^{8}$ a psicogeografia é definida como materialista se precavendo do ocultismo (termo escolhido por eles) que poderia minar a realização de uma psicogeografia crítica, que tomava como premissa o materialismo dialético para se efetivar. O termo se faz relevante pois estabelece as condições, bem como o método de análise, proposto pela psicogeografia letrista/situacionista. No texto, já citado aqui, em que Debord traça suas críticas à geografia urbana, o autor escreveu:

A palavra psicogeografia, proposta por um cabila analfabeto para designar o conjunto dos fenômenos observados por nosso grupo no verão de 1953, tem sua razão de ser. Faz parte da perspectiva materialista do condicionamento da vida e do pensamento pela natureza objetiva. (JACQUES, 2003, p. 39)

Não se trata de compreender a sensação movendo a realidade, mas sim da realidade se impondo e criando texturas, (im)possibilidades sobre as sensações. A psicogeografia (materialista) expõe que existem densidades diferenciadas, sendo que estas densidades possuem uma poderosa capacidade de influenciar das mais variadas formas os ambientes. A psicogeografia não pode ignorar nenhum momento da vida. Colocada no

\footnotetext{
${ }^{7}$ Inúmeras tentativas subversivas foram postas em curso com os mapas. Membros da I.S percorreram cidades usando mapa de outras. Debord recortou fragmentos de mapas e os ligou aleatoriamente, ou ainda criando novas intersecções a partir de derivas e ações psicogeográficas.

${ }^{8}$ DEBORD, 1996, p. 227.
} 
nível do sujeito ela tem a capacidade de evidenciar as qualidades e defeitos dos lugares vívidos. Tendo em vista que a forma de reprodução do capital abarcou o cotidiano a psicogeografia torna-se uma ferramenta potente no desvendamento desse processo. A vacância posta pela psicogeografia na cidade não buscaria desvendá-la, senti-la, em toda sua dimensão castradora que inviabilizava (e segue inviabilizando) a vida por meio do fenômeno particular e destituído da totalidade, mas sim pelo movimento do capitalismo se reproduzindo ao (re)produzir o urbano. Assim a psicogeografia (materialista) ia (vai) em busca de compreender os resultados (práticos, afetivos, sentimentais) da produção capitalista do urbano. Identificado todo este peso morto sobre o vivido, a psicogeografia se colocava também como um instrumento de transformação possível, usual.

De pronto, dito isto, é importante destacar que quando se tenta utilizar a psicogeografia como concepção de trabalho de campo almeja-se avançar na identificação da produção do espaço urbano e de sua necessária relação (de imposição, de castração, de redução) com o vivido. Portanto, As tentativas de descrição psicogeográficas se valeram do que os letristas chamaram de psicogeografia materialista, reforçando a ideia de que as sensações e sentimentos produzidos pelo e no urbano são decorrentes dos processos e da forma com que o capitalismo se valeu da (re)produção do espaço para se reproduzir; e não de uma mera apreensão sensorial e instantânea do problema. Ou seja, a forma de produzir a cidade é aquela posta pelo capital e a psicogeografia pode auxiliar no entendimento desta relação se colocando como condição de reprodução da sobrevivência ampliada, da não vida na cidade contemporânea. Convém salientar ainda que a combinação da deriva com a psicogeografia não é, nem de longe, uma tentativa iniciada nesta pesquisa. Ela tem sido aplicada, sobretudo nos estudos de Geografia Urbana, já há alguns anos ${ }^{9}$, em variadas pesquisas realizadas no Departamento de Geografia da Faculdade de Filosofia Letras e Ciências Humanas da Universidade de São Paulo se estabelecendo como um caminho potente de trabalho de campo.

\section{A Deriva}

Os letristas/situacionistas em seu conjunto de propositivas prático-teóricas entendiam que o entrecruzamento da cidade e do cotidiano era de suma importância no projeto de transformação total e profunda da vida e do mundo. Não é à toa que muitas das atividades propostas e realizadas por estes grupos se voltavam para a tentativa de usar e subverter a cidade. A deriva foi, neste sentido, uma poderosa aposta pois oferecia a possibilidade de, simultaneamente, realizar o emprego qualitativo do tempo no espaço urbano de modo lúdico e identificar todo o peso do planejamento capitalista no espaço ${ }^{10}$. Então a deriva se colocou como uma prática-teórica dialética pois oferecia a chance de resignificar e realizar o jogo, o lúdico, em uma nova dimensão (tarefa entendida como

\footnotetext{
${ }^{9}$ Exemplos notórios são os trabalhos de SILVA, 2004 e de MAGALHÃES, 2011.

${ }^{10}$ Merece ser lembrada também a importante influência, menos de conteúdo e mais de método, do sociólogo Paul-henry Chombart de Lauwe e de seu livro Paris et l'agglomération parisienne, de 1952. Este autor chega a ser citado nominalmente por seus estudos e um diagrama de seu livro é publicado na I.S no texto que aborda as derivas de Rumney em Veneza.
} 
primordial desde o início da I.L até os últimos momentos da I.S) e, ao mesmo tempo, possibilitava avançar na caracterização e no entendimento do que chamaram de "relevo psicogeográfico", onde era possível aprofundar o entendimento das ambiências urbanas sobre o corpo e sobre a alma.

A deriva foi definida, já na primeira revista da I.S ${ }^{11}$, como "Modo de comportamento experimental ligado às condições da sociedade urbana: técnica da passagem rápida por ambiências variadas. Diz-se também, mais particularmente, para designar a duração de um exercício contínuo dessa experiência." (I.S n. 1, p. 17). A deriva enquanto técnica atuava, simultaneamente, identificando toda a pobreza estruturada na cidade funcional, o reino do tédio e da sobrevivência, ao passo que também oferecia uma forma de usar a cidade que flertava, que oferecia possibilidades de transformação do mundo. Aqui é preciso ressaltar que a busca revolucionária letrista/situacionistas não se limitava ao modo como a esquerda tradicional compreendia e buscava realizar a revolução. Letristas e Situacionistas se dedicavam a traçar novas estratégias de pôr em curso o projeto revolucionário e a deriva, bem como outras práticas, oferecia esta pulsão pois possibilitava a realização de um verdadeiro e transformador laboratório que entrecruzava a cotidianidade presente com o projeto de transformação total da vida. A deriva oferecia não só um caminho que poderia estar inserido - e já em curso - na transformação, como também já desenha possibilidades para a posterioridade da revolução; isso porque os situacionistas (fato que também os difere de grande parte da esquerda) não aceitavam a ideia de que só depois de destruir o capitalismo que chegaria a hora de pensar e realizar o projeto da vida em sua totalidade. Por isso a técnica da deriva, como algumas outras propositivas situacionistas ofereciam uma estratégia possível de contraposição ao mundo enquanto tal e, ao mesmo tempo, uma possibilidade já em curso para mundo e a vida que desejavam depois da revolução. Neste aspecto, a deriva (como também a psicogeografia e a situação) é um elo que realiza no presente o futuro que se deseja construir ${ }^{12}$.

\footnotetext{
${ }^{11}$ Nesta revista os situacionistas escreveram um glossário (intitulado Definições) aonde foram explicadas algumas das formas de ação do grupo como, por exemplo, a deriva, a psicogeografia, o urbanismo unitário, a situação construída, o desvio e a decomposição.

12“'Outros tipos semelhantes de experiências ou simples reflexões sobre o espaço urbano provocavam ou consideravam a própria experiência estética ou a apreensão efetiva desses espaços. Podemos tentar traçar uma linha de artistas e teóricos que viria desde Charles Baudelaire, da ideia de flâneur (em 1893, no texto Le peintre de la vie moderne), passando pelos dadaístas com as excursões urbanas por lugares banais, as deambulações aleatórias organizadas por Aragon, Breton, Picabia e Tzara, entre outros, que continuaram com os surrealistas liderados por Breton, pela experiência física da errância no espaço real urbano que foi a base dos manifestos surrealistas (e dos livros Le paysan de Paris de 1926 de Aragon e Nadja de 1928 e L'amour fou de 1937, ambos de Breton), que desenvolveram a ideia de hasard objectif; depois disso, Walter Benjamin retomou o conceito de flâneur de Baudelaire e Aragon, e começou a trabalhar a ideia de flnerie, ou seja, de flanâncias urbanas, a investigação do espaço urbano pelo flâneur principalmente de Paris e de suas passagens cobertas no Le livre des passagens). Apesar de o flâneur ser para os situacionistas o protótipo do burguês entediado e sem propostas, e da tentativa desde de se distanciarem das, segundo eles, promenades imbéciles surrealistas, os surrealistas contribuíram para desenvolver essa mesma ideia ao propor a noção de deriva urbana, da errância voluntária pelas ruas. Sem dúvida existiu uma grande influência dadaísta, por exemplo da famosa excursão dadaísta - sempre propostas em lugares escolhidos precisamente por sua banalidade e falta de interesse - à igreja Saint-Julien-le-Pauvre em Paris, que ficou conhecida como lère Visite e ocorreu na quinta-
} 
A deriva e a psicogeografia formam uma poderosa e indissociável dupla. Já nas primeiras linhas do texto "Teoria da deriva"13 (I.S n. 2) Debord lembra que "O conceito de deriva está indissoluvelmente ligado ao reconhecimento de efeitos de natureza psicogeográfica e à afirmação de um comportamento lúdico construtivo, o que o torna absolutamente oposto às tradicionais noções de viagem e de passeio.”. Mais à frente, ele diz "As lições da deriva permitem estabelecer os primeiros levantamentos das articulações psicogeográficas de uma cidade moderna” (I.S, n. 2, p. 52).

No texto "Résumé 1954" publicado ainda na revista Les lèvres nues Debord e Fillon ressaltam a busca por uma prática simultaneamente transformadora e lúdica.

As grandes cidades são favoráveis à distração que chamamos de deriva. A deriva é uma técnica do andar sem rumo. Todas as casas são belas. A arquitetura deve ser apaixonante. Nós não saberíamos considerar tipos de construção mais restritivas. O novo urbanismo é inseparável das transformações econômicas e sócias felizmente inevitáveis. É possível se pensar que as reivindicações revolucionárias de uma época correspondem à ideia que essa época tem de felicidade. A valorização dos lazeres não é uma brincadeira. Nós insistimos que é preciso se inventar novos jogos. (JACQUES, 2012, p.179)

É possível ver claramente neste trecho que o ideário de transformação do mundo situacionista tem no lúdico um pilar fundamental. Também é relevante notar o esforço em buscar a ligação entre a cidade e novas formas de jogo inerentes a ela e fluentes na cotidianidade.

Em outro momento de "Teoria da Deriva” Debord afirma que "A parte aleatória não é tão determinante quanto se imagina: na perspectiva da deriva, existe um relevo psicogeográfico das cidades, com correntes constantes, pontos fixos e turbilhões que tornam muito inóspitas a entrada e saída de certas zonas" (JACQUES, 2003, p. 87). Debord deixa latente a dificuldade (para não dizer a impossibilidade) de se perder na cidade, de vagar livremente. $\mathrm{O}$ peso das estruturas, do planejamento funcionalista, do urbano como um todo, no limite, inviabiliza a concretização lúdica da deriva. A aleatoriedade sucumbe diante do concreto.

Mais além disso, a rispidez da cidade com que se deparavam os situacionistas não permitia que a técnica da deriva fosse realizada em sua plenitude e nem tão pouco sem produzir danos às vezes irreparáveis aos seus praticantes, como foi o caso de Ralph Rumney (ver "Veneza venceu Ralph Rumney" em I.S n. 1) que também pode ser vista no trecho escrito abaixo por de Gilles Ivain:

feira, 14 de Abril de 1921 às 15 horas, quando Breton leu um manifesto para épater les bourgeois" (JACQUES, 2003, pp. 34-35).

${ }^{13}$ Teoria da Deriva, foi originalmente publicado em 1956 na Les Lèvres nues, revista belga, ainda considerada surrealista naquela época. 
[...] A deriva (na seqüência dos atos, com seus gestos, seu passeio, seus encontros) era exatamente na totalidade o que a psicanálise (a boa) é na linguagem. Deixe você se levar pelo desenrolar das palavras, diz o analista. Ele escuta, até o momento em que ele denuncia ou modifica (pode se dizer desvia) uma palavra, uma expressão ou uma definição. A deriva é voluntariamente uma técnica, e quase uma terapia. Mas como a análise sem outra coisa - por si só - é quase sempre contra-indicada, da mesma forma a deriva contínua é um perigo na medida em que o indivíduo avança muito longe (não sem base, mas...) sem proteções, é ameaçado de explosão, de dissolução, de separação, de desintegração. E é a retomada no que se nomeia "a vida corrente", isto é claramente "a vida petrificada". Nesta medida, eu denuncio agora a propaganda por uma contínua deriva do Formulário. Sim, contínua, como o jogo de poker em Las Vegas, mas contínua por um tempo, reservada ao domingo para uns, a uma semana numa boa média; um mês, é muito. Nós praticamos, em 1953-54, três ou quatro meses; é o limite extremo, o ponto crítico. É um milagre nós não estarmos mortos. Nós possuímos uma má saúde de ferro. (I.S n. 9, p. 365) ${ }^{14}$

\section{Considerações finais}

Convém evidenciar, uma vez mais, que, como no caso da psicogeografia, o uso da deriva tem sido uma ferramenta difundida nos estudos de Geografia Urbana, sobretudo em parte das pesquisas realizadas no Laboratório de Geografia Urbana da Universidade de São Paulo (Labur-USP), mais notoriamente entre os frequentadores do grupo de estudo dos Situacionistas ${ }^{15}$.

O estudos e usos metodológicos das práticas e propositivas situacionistas carregam, dentro da universidade, um inevitável esvaziamento visto que quanto executada pelos situacionistas tinha uma outra dimensão que agora se perde ao ser transformada e realizada como método de trabalho de campo, sendo assim destituída de sua pulsão lúdica e transformadora para se restringir à análises de ordem científica. Todavia, ainda assim, a prática da deriva, atrelada a psicogeografia, viabiliza experimentações e possibilidades consideráveis para o desvendamento crítico da realidade sócio espacial, mais

\footnotetext{
${ }^{14}$ Ivan Chtcheglov em Cartas de Longe. IS, n. 9, ago. de 1964. Trata-se de Gilles Ivain, que em 1953 escreveu Formulário para um urbanismo novo, quando tinha 19 anos. Passou mais de 5 anos em clínica psiquiátrica. Os situacionistas o consideram vítima da modernização da sociedade que levou ao controle da vida. No momento deste fragmento de carta, tentava reescrever o texto sobre arquitetura e urbanismo de 53.

${ }^{15} \mathrm{O}$ grupo existe a cerca de treze anos nas dependências do Labur e conta com a orientação da professora Amélia Luisa Damiani que também em seus cursos de graduação e de pós-graduação fornece textos e debates a cerca das derivas.
} 
notadamente em áreas urbanas, e já não pode mais ser desconsiderada ou desprezada como técnica de trabalho de campo em Geografia Urbana.

Que a cidade seja este imenso e contraditório campo de experimentações!

\section{Referências bibliográficas}

DEBORD, G. A sociedade do espetáculo. Rio de Janeiro: Contraponto, 1997.

DEBORD, G. Potlach (1954-1957). Paris: Gallimard, 1996.

DEBORD, G. Relatório sobre a construção de situações e sobre as condições de organização e de ação da tendência Situacionista Internacional. Cosio d'Arroscia, 1957.

FELGUERAS (coletivo). Esse imbecil llamado Sartre: antologia de insultos publicados em Internationale Situationniste. Madri: Ediciones La Felguera, 2008.

HUIZINGA, J. Homo Ludens. São Paulo: Perspectiva, 2005.

INTERNATIONALE SITUATIONNISTE. Paris: Arthème fayard, 1997.

INTERNACIONAL SITUACIONISTA, Textos íntegros en castellano de la revista Internationale Situacionniste (1958-1969). Madri: Traficantes de Sueños, 2004.

INTERNACIONAL SITUACIONISTA, Sessão Inglesa, La Rioja, Pepitas, 2007.

INTERNAZIONALE SITUAZIONISTA, Sessão Italiana, La Rioja, Pepitas, 2007.

JACQUES, P. B. (org.). Apologia da Deriva. Escritos situacionistas sobre a cidade. Rio de Janeiro: Casa da Palavra, 2003.

JAPPE, A., Guy Debord. Paris: Via Valeriano \& Editions Sulliver, 1998.

JAPPE, A. L'Avant-Garde Inacceptable: Reflexions sur Guy Debord. Paris: Éditions Lignes, 2004.

JORN, A. Pour la forme. Paris: Allia, 2001.

MAGALHÃES, F. L. B. M. Ideias provisórias para tempos provisórios: A trajetória da Internacional Situacionistas e apontamentos para seu lugar na Geografia. Dissertação de Mestrado, FFLCH, USP, São Paulo2011.

SILVA, F. E. Aproximar sem reduzir: as derivas e a pesquisa de campo em geografia urbana. GEOUSP - Espaço e Tempo, São Paulo, No 15, pp. 139-149, 2004.

VANEIGEM, R. A arte de viver para as novas gerações. São Paulo: Conrad, 2002.

VASCONCELLOS, R. P. Cidade Máquina/Projeto \& Utopia: Ensaio de crítica espacial ao construtivismo russo. Monografia de conclusão de curso em Geografia, FFLCH, USP, São Paulo, 2015. 
Glauco Roberto Gonçalves

Professor da Universidade Federal de Goiás, doutor em Geografia Humana pela Universidade de São Paulo. Mestre em Geografia Humana pela Universidade de São Paulo, bacharelado e licenciatura em Geografia pela Universidade de São Paulo.

Este texto é fruto de pesquisa financiada pela FAPESP.

Email: glauco.goncalves@ufg.br

Recebido para publicação em dezembro de 2018 Aprovado para publicação em março de 2019 